\title{
PLEOMORPHIC ADENOMA
}

\section{By Mahendeka Sikudhani, DDS 5 2008/2009 (MUHAS), School of Dentistry.}

\section{INTRODUCTION}

Pleomophic adenoma is a mixed benign tumor which is the most common of all salivary gland neoplasms. It's most common location is the parotid gland (85\%). This tumor is mostly diagnosed in the 4th-6th decades of life.

Clinically, it presents as a slowly growing, painless, firm mass. It tends to be mobile when small but may become fixed with advanced growth. Usually, it shows a smooth lobulated appearance.

This is a case of a 68 year-old man from Tanga who was suffering from pleomophic adenoma for 6 years. The tumor started as slowly growing mass which increased to attain a shiny, lobulated appearance. The patient had been treated unsuccessfully by various tradition healers. Finally, he went to Teule Hospital were he was referred to Muhimbili National Hospital (MNH) for further investigations and management. At MNH, a fine needle aspiration was done and a diagnosis of pleomophic adenoma was made. The tumor was surgically removed and the patient recovered with good prognosis.

\section{CASE DESCRIPTION}

Patient's Particulars

Name: BS

Age: 68 years

Sex: Male

Residence: Tanga

\section{Chief Complaint}

The patient was complaining of a painless swelling on the left side of the face for 6 years.

\section{History of Presenting Illness}

The patient was apparently well until early 2002 when he noticed a slowly growing lump near his left earlobe. As the swelling became noticeable and obstructive during mouth opening, he went to Teule Hospital where he was given some medication to relieve the swelling. The swelling did not decrease, and he started seeking traditional therapy unsuccessfully for about three and a half years. He returned to Teule Hospital in 2007 where he was referred to Muhimbili National Hospital (MNH) for further investigations and management.

\section{Medical History}

The patient's medical history was unremarkable except for occasional headaches an slight difficult in swallowing due to the tumor.

\section{General Examination}

He was an ill- looking man, not pale, not jaundiced and well oriented in time and place. He had facial asymmetry due to a swelling on the left side of the face. 


\section{Provisional Diagnosis}

Pleomorphic Adenoma

\section{Differential Diagnoses}

Mucoepidermoid carcinoma

Warthin's tumor

\section{Investigations}

Routine investigations:

Full blood picture

Erythrocyte sedimentation rate

Stool examination

Urinalysis

Specific investigation

Fine needle aspiration

Diagnosis: pleomophic adenoma

\section{Management}

Elective surgery, in which surgical removal of the tumor was successfully done.

\section{Patient at presentation}
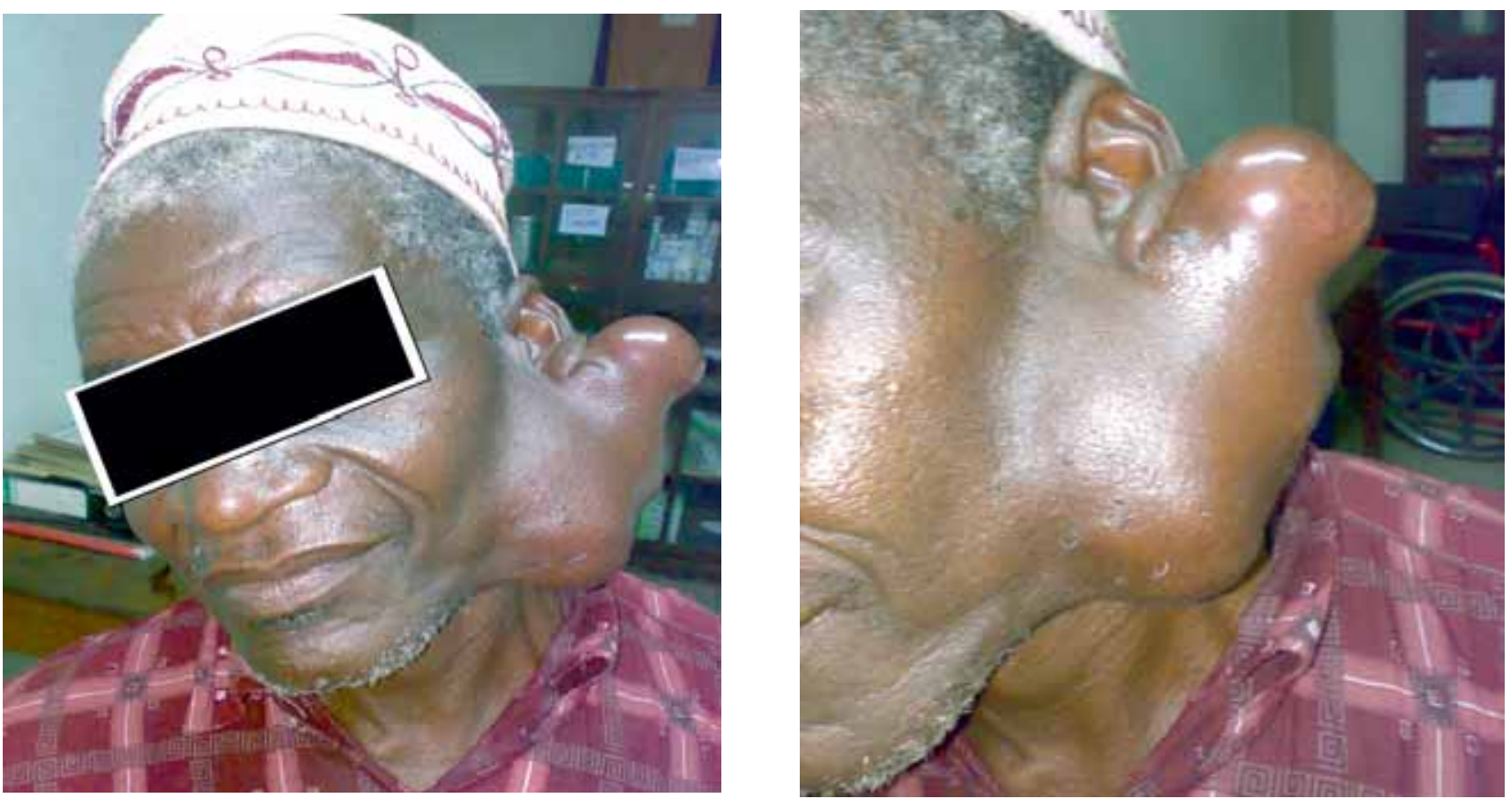

Close view of the tumor anteriorly 


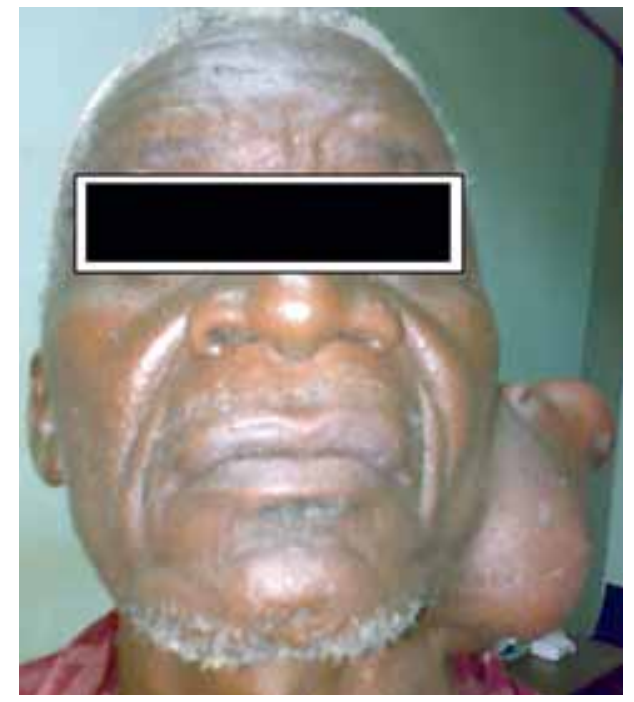

Close view of the tumor posteriorly

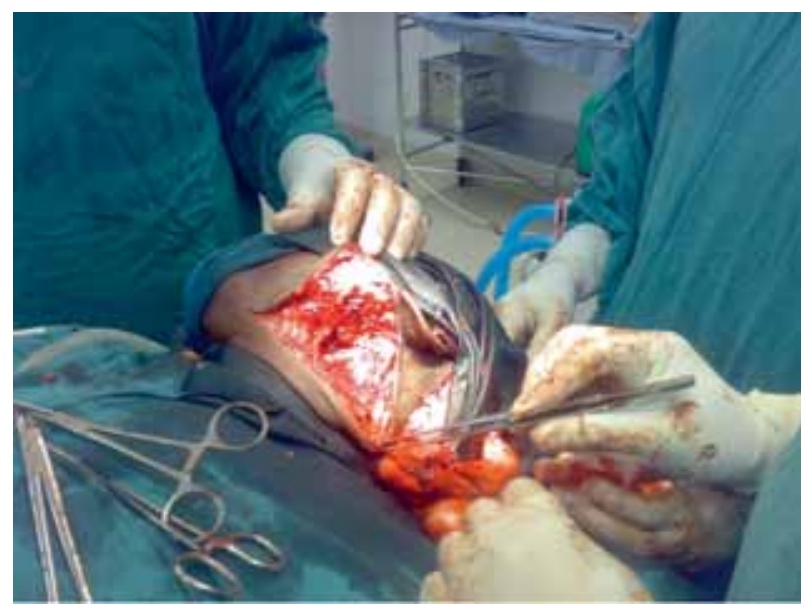

Surgical removal of the tumor

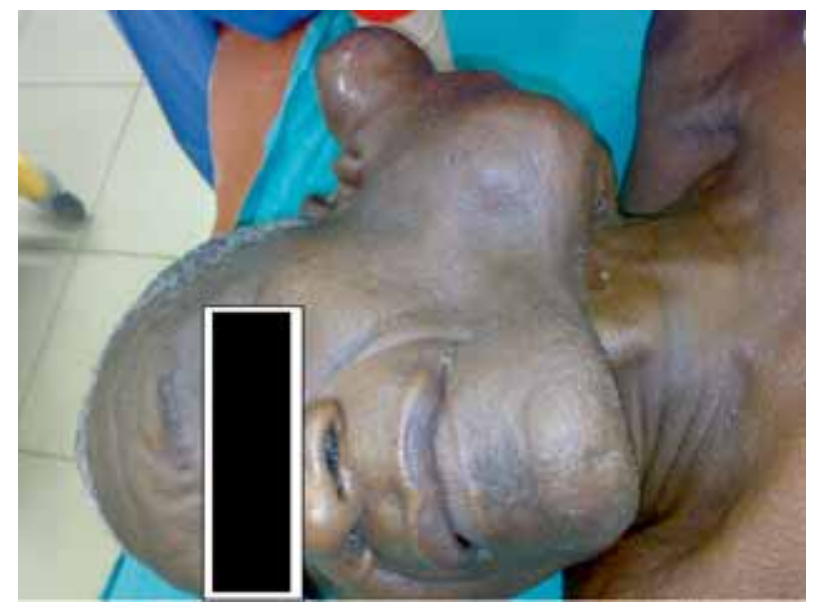

Front view with the patient lying on one side

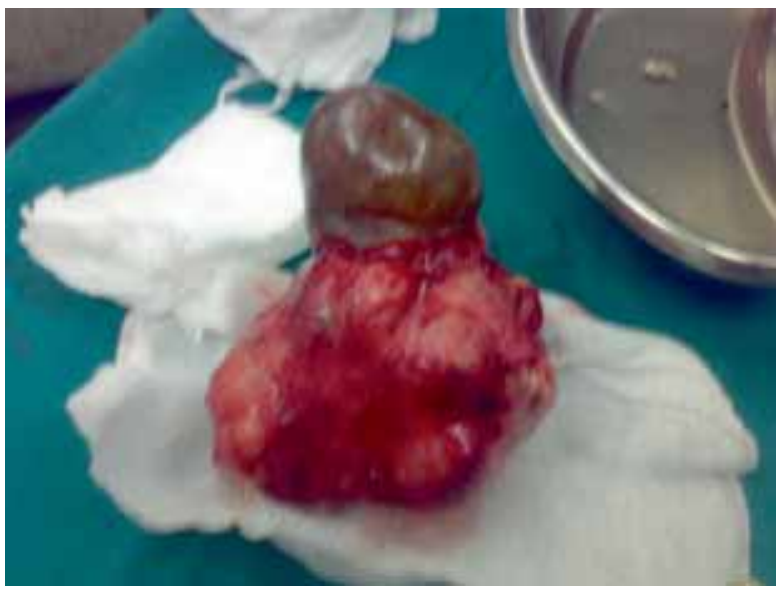

The tumor after removal

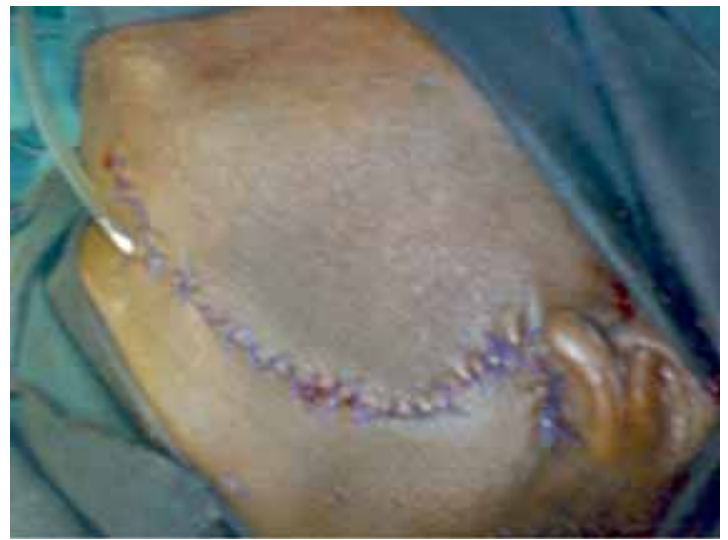

The patient after surgery

\section{References}

1. Wuehmann A H. Manson-Ling R L. Dental Radiography. 4th ed. 1977, pg. 407.

2. Sanders b. Paediatric oral and maxillofacial Surgery, 1979; 255-256. 